\title{
EL MUSEU A DISPOSICIÓ DE L’ESCOLA
}

\author{
Marisa Suárez Barral. Museu d'Art Modern de Tarragona. \\ Rosa Ayxendri Gairal. CEIP de Pràctiques de Tarragona
}

\section{Un projecte en comú}

El Servei Pedagògic del Museu d'Art Modern de Tarragona (MAMT), dins la seva oferta educativa dirigida a les escoles, estableix línies de cooperació i col-laboració entre els docents i el museu amb la programació d'un ampli ventall d'activitats i tallers que permeten donar cobertura a la difusió i coneixement de les col-leccions permanents, les exposicions temporals i les activitats proposades per treballar en l'espai públic, la qual cosa ens permet conjugar art, museu i territori (MACAYA i SUÁREZ, 2007).

La consolidada trajectòria de relacions que manté el Servei Pedagògic del museu amb les escoles de la demarcació de Tarragona és el que ens fa amatents a les propostes educatives que es produeixen més enllà de les mateixes parets del museu. Escoltar les veus dels diferents col-lectius socials i ser receptius a les seves demandes $\mathrm{i}$ inquietuds ens permet configurar una xarxa que possibilita l'intercanvi i el coneixement mutu. "Potenciar la missió educativa, dinamitzar el museu i la seva projecció sobre l'entorn social són, igualment, algunes de les finalitats que tenen assignats els Departaments d'Educació i Acció Cultural" (HERNÁNDEZ, 1994).

Fruit d'aquesta interrelació es va iniciar un nou projecte interdisciplinari i de col-laboració proposat des del CEIP de Pràctiques de Tarragona, que sota el títol: Imagina't que ets un artista... i que exposes al MAMT, s'elaborà durant el curs 2006/2007. Es responia així a la inquietud per part de l'escola, que demanava una participació més activa en el camp de l'educació artística i volia aportar les seves idees i propostes de treball. No volia limitar la seva relació amb el museu només amb les visites pedagògiques i els tallers, sinó que podia parlar dels objectes en primera persona des de les seves pròpies experiències aportant el seu coneixement i criteri mitjançant l'elaboració de la producció artística, reinterpretant les obres i participant activament en l'engranatge del disseny i muntatge expositiu. Per això es preguntava: per què els nens i les nenes no disposen d'un espai en el museu?

Aquest procés de treball s'estructurà en reunions prèvies a les visites al museu entre els diferents agents que participaren en el projecte: les mestres, els alumnes, les educadores i el personal del museu. També es va comp- tar amb la participació i cooperació de l'artista Antonio Alcàsser, que va realitzar una visita a l'escola i explicà en primera persona el procediment i concepte de la seva obra, objecte d'estudi per part d'un sector dels alumnes del centre.

Les negociacions van generar un camp de forces, on avinences i desavinences, acords i desacords prenien protagonisme i donaven pas a la reflexió i el debat, on els dubtes i els encerts deixaven oberts molts interrogants que estimulaven noves formes de relacions entre l'escola i el museu: com s'elaboraria el programa de treball?, com es creuarien les mirades entre l'escola i el museu?, com s'implicarien tots els subjectes que participaven en el projecte?, com s'articularia des de l'escola?, i la institució museística, quins objectius perseguia?

\section{El museu, un espai per compartir}

EI MAMT és un museu de dimensions mitjanes, amb unes col-leccions formades per artistes vinculats directament amb el territori. Es tracta d'un espai reconegut i referent dins de la producció cultural de la demarcació de Tarragona. Des del Servei Pedagògic s'ofereix i amplia la programació educativa a la comunitat amb la finalitat d'apropar els seus continguts, propiciant el diàleg amb els diferents públics. Des d'aquesta perspectiva, si considerem el museu com un lloc que legitima la producció dels artistes, la col-laboració i el treball dels alumnes ens permet copsar un nou enfocament i tractament en l'anàlisi de les obres, i ens dóna com a resultat un canvi en la concepció de l'espai del museu i una nova dimensió en el seu paper de transmissor i productor de cultura. L'elaboració d'un projecte educatiu implica establir des del museu quins són els principals objectius que es volen assolir i quines metodologies aplicarem en els processos de treball que ens ajudin en l'avaluació posterior de l'activitat.

Per al projecte: Les escoles exposen al MAMT vam contemplar els següents punts:

- Oferir a les escoles un espai per compartir l'experiència de conèixer el MAMT; no tan sols amb les activitats i tallers proposats des del museu, sinó donar la possibilitat d'oferir i utilitzar el museu, apropiant-se de la seves infraestructures i reinterpretant els objectes. 


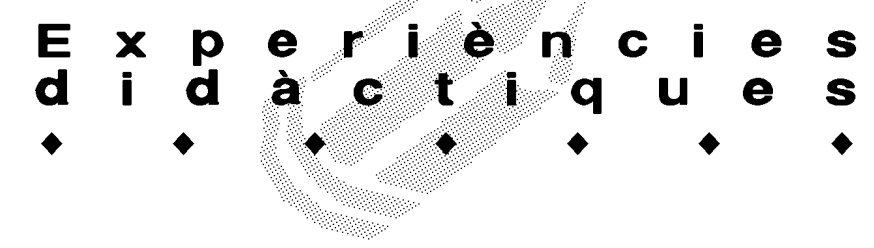

- Cooperar amb els docents i assessorar-los per a un millor desenvolupament de la seva tasca com a professionals de l'educació. Una de les funcions educatives del museu és la de proporcionar als mestres i professors eines i pautes per desenvolupar i treballar les activitats en matèria d'educació visual i plàstica, i elaborar, mitjançant els programes i les activitats educatives, continguts i procediments relacionats amb el currículum escolar.

- Participar amb els mateixos artistes en el projecte a l'escola per afavorir i estimular les facultats creatives dels alumnes.

- Incidir en la importància de l'educació artística per al desenvolupament cognitiu dels nens i de les nenes. Mostrar i oferir el museu, des de l'educació no formal, com un lloc comú i d'intercanvi, un Iloc per a l'aprenentatge on puguin desenvolupar-se i expressar-se a través dels objectes, un lloc on la interrelació entre els companys i els mestres els ajudi a formar-se com a persones, i redescobrir, acompanyats dels seus familiars, un espai quotidià del seu entorn.

\section{Des de l'escola}

La participació íntegra del CEIP de Pràctiques, collectiu format per 435 alumnes d'entre 3 i 12 anys, 18 tutors d'aula, 3 coordinadors de cicle, 1 assessora en matèria d'educació visual i plàstica i 1 coordinador de l'escola, obligà a renegociar conjuntament el calendari de visites i de les activitats proposades, amb la finalitat d'establir els processos de treball.

Durant la primera reunió de coordinació es negocià l'espai del museu on s'acolliria el projecte i la seva durada, que seria d'un mes, coincidint amb el final del curs acadèmic. Posteriorment per a cada nivell educatiu es programaren reunions amb les mestres. Aquestes trobades ens ajudaren a seguir les pautes d'actuació per a la posterior visita al museu, desenvolupant metodologies i recursos pedagògics, diversificant i ordenant temàticament les activitats.

La manera de treballar dels diferents cicles, Educació infantil i Educació primària, ha condicionat, com es lògic, aquest treball, i aquest fet queda reflectit en el resultat final.

En l'Educació infantil (P3, P4, P5) el treball és globalitzat; la tutora s'encarrega de la majoria d'àrees i aquest fet facilita la interdisciplinarietat. No ens cal separar les àrees, podem treballar un mateix tema (en aquest cas, d'art) des de totes les àrees. Aquest fet ens porta a un projecte on es treballa:

- Descoberta d'un mateix.

- Descoberta de l'entorn.

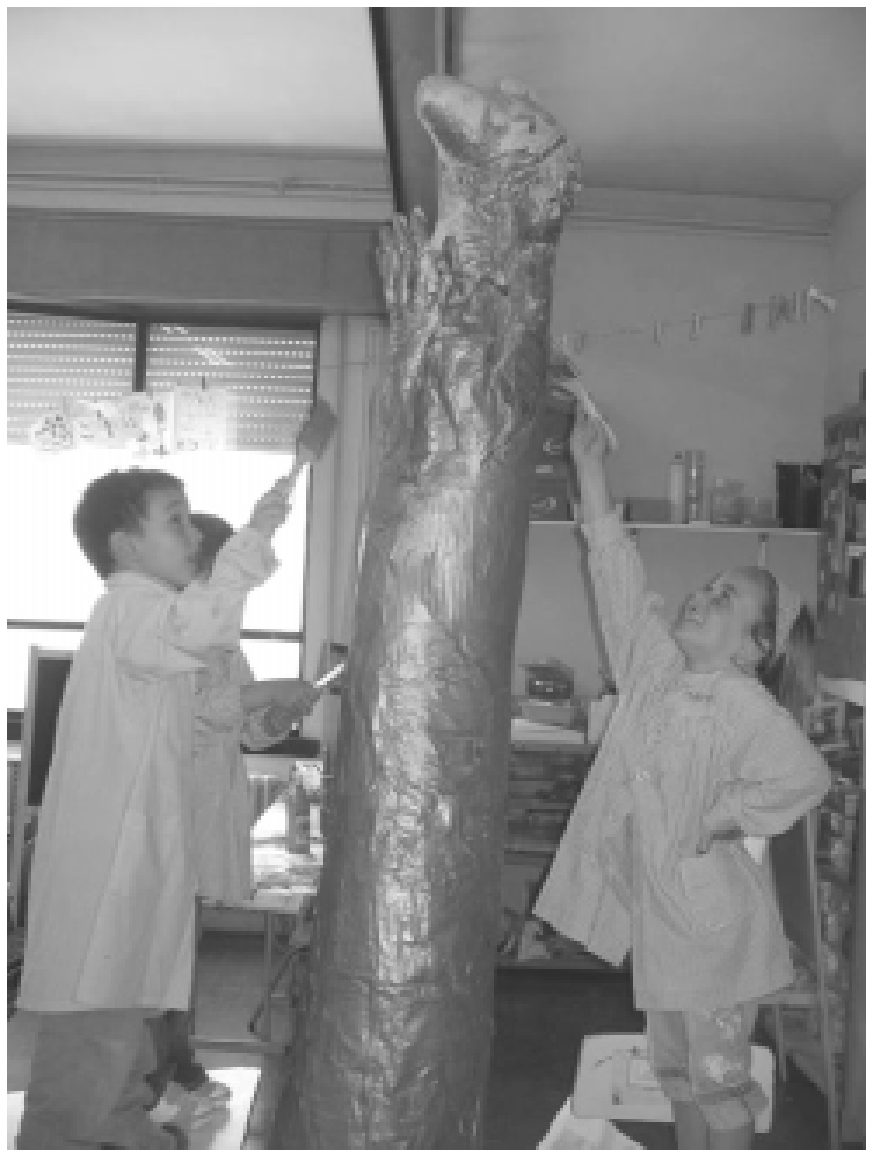

- Llenguatges (entre ells, el plàstic).

A l'Educació primària les àrees estan molt diferenciades. Els horaris, els llibres de text i els canvis de professors segons les àrees ens porten a una dinàmica diferent.

El treball de l'obra s'ha fet dins de l'àrea de plàstica, en el seu horari setmanal i des del punt de vista estrictament artístic.

El següent pas va ser el repartiment dels temes triats, que es distribuïren segons els diferents nivells:

Educació infantil.

Infantil 3 anys: amb el projecte: "Les formes i els colors" es treballaren conceptes geomètrics (el cercle, el triangle i el quadrat) i els colors.

Infantil 4 anys: es va realitzar el projecte "Retrat" prenent especial importància l'autoretrat i els sentiments que expressem amb la cara.

Infantil 5 anys: es treballà l'escultura a partir del projecte "Thales", activitat plantejada conjugant dos àmbits diferents: el carrer on s'estudià la ubicació del monument, i les sales del museu, on es treballà a partir de la maqueta de la mateixa escultura.

Educació primària.

Cicle inicial: s'investigà sobre el paisatge rural i urbà, 


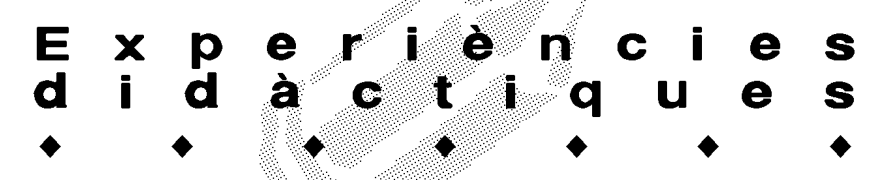

a partir de la tècnica del collage, grattage i frottage.

Cicle mitjà: a partir de la proposta de treball de l'artista Antonio Alcàsser amb la seva obra Projecte d'Arbres IV, es va aprofundir de manera subjectiva en el concepte de l'obra i relacionar i comparar els arbres amb les persones.

Cicle superior: es treballà els conceptes de composició i ritme amb la tècnica del collage i s'investigaren les diferents tècniques, materials i eines escultòriques a partir de l'obra de l'escultor Julio Antonio.

Des de l'escola i mitjançant el lloc web (http://mamtpe dagogic.altanet.org/\#), es podien consultar els diferents temes adaptats als nivells educatius. Aquesta eina de treball ens permetia abordar de forma general un tema, per després posar l'accent en una obra concreta de la col.lecció. D'aquesta manera es treballen conceptes, procediments i actituds referits a les obres seleccionades.

\section{La visita al museu}

El calendari va marcant el ritme de treball. Abans de començar les activitats, mestres, alumnes i educadores ens reunim en un espai del museu on s'expliquen aspectes referits als continguts i la durada de la visita. Es tracta d'un moment important: en aquesta xerrada s'estimula els alumnes a familiaritzar-se amb el personal del museu i també ens permet copsar les inquietuds i necessitats del grup. Des de l'escola la reunió prèvia amb els tutors ha permès determinar què es treballarà i com s'iniciaran les activitats. Enguany, motivats per la novetat del projecte, es tracta d'una visita especial: els artistes del MAMT són el seu mirall, els alumnes també són artistes i ho han de demostrar.

Les activitats es desenvolupen directament a les sales del museu. L'espai està concebut per asseure's i treballar davant les obres. L'emoció i la intensitat que es transmet amb aquesta experiència fa augmentar el grau d'expressivitat i creativitat del nen. L'experiència artística del nen desenvolupa els seus sentits i promou la seva percepció. L'espai, les formes, els colors, les textures, els sons i

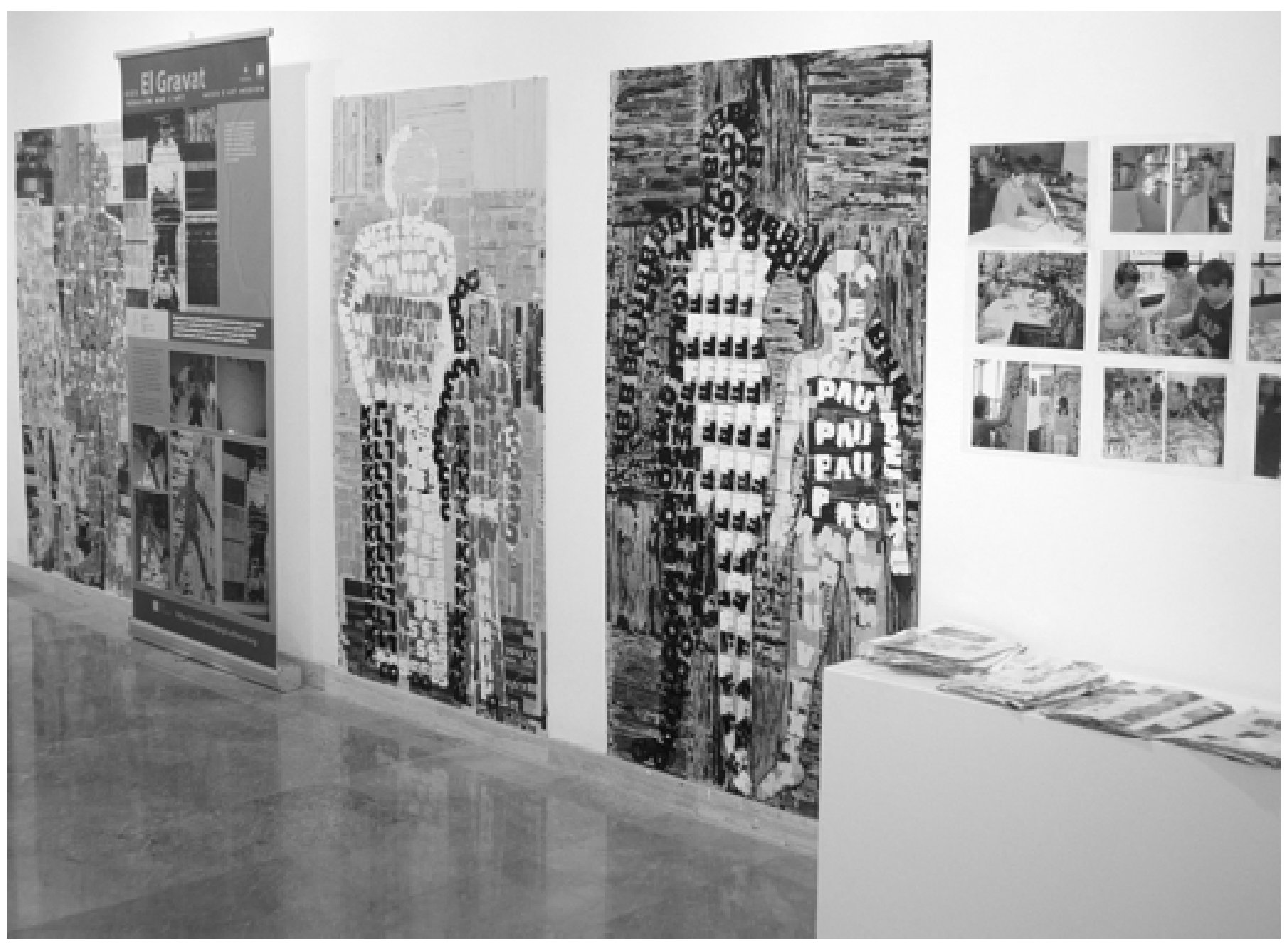




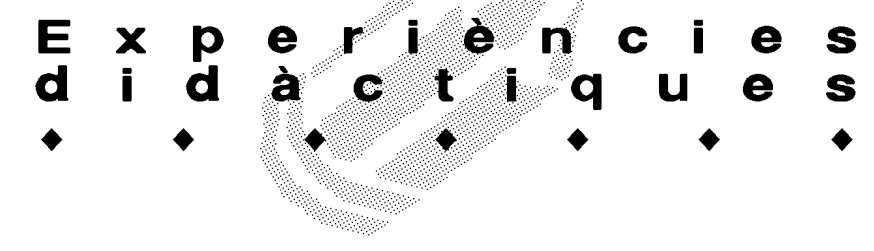

les experiències visuals inclouen tota una varietat d'estímuls per a l'expressió. L'art afavoreix enormement el desenvolupament creador del nen, i així, al crear, es posen en joc habilitats d'anàlisi, de selecció, d'associació i de síntesi.

L'estratègia es basa en l'aprenentatge per descobriment. Mitjançant fotografies, textos i altres recursos pedagògics es dóna pas a preguntes mediadores que ens permeten enllaçar la conversa, copsar l'atenció de l'alumne, provocar la reflexió i l'observació de les obres. Aquestes preguntes faciliten el diàleg i el contrast de diferents opinions entre alumnes, educadores i mestres, i la relació amb situacions afectives per desenvolupar mecanismes d'associació, on cadascú aporti la seva apreciació i coneixement envers les obres (PADRÓ, 2005). Posteriorment, les activitats proposades al Museu ens porten a situacions de discrepàncies i coincidències entre el docent i l'alumne, i entre els mateixos alumnes, per veure com cadascuna ha de ser valorada i respectada. La realització dels diferents tallers al museu beneficia també el desenvolupament emocional del nen, propiciant l'acceptació de si mateix amb les seves possibilitats i límits, enfrontant-se a múltiples formes d'interrelació en les quals es conjuga el treball individual i el col-lectiu en un continu procés de donar i rebre, demanar i cedir, dirigir i seguir, cooperar i comprendre les altres individualitats amb les seves diferències i necessitats.

En la majoria de museus la concepció de l'exhibició i del disseny expositiu dificulta la visió i apreciació de les obres per part del públic escolar. Creiem que una bona disposició i l'apropament directe dels objectes els fa més comprensibles; l'objectiu és fer habitable un espai de reverència a partir de tàctiques d'apropiació (DE CERTEAU, 1990). L'acte d'ensenyar una escultura, baixar-la del pedestal, o obrir una vitrina per fer-la accessible a la mirada del nen, interactuant i desenvolupant les seves capacitats sensorials, estimula i propicia la comprensió de l'objecte. (PASTOR, 2004).

\section{Moltes veus, un únic projecte expositiu}

Posar en solfa aquest projecte va ser una tasca àrdua. Havíem de sincronitzar totes les veus i posicionarnos davant del treball col-lectiu i de la cooperació de tot l'equip. Les educadores del museu jugàvem amb cert avantatge en relació amb els alumnes. D'una banda, no érem subjectes que avaluàvem els seus treballs, ni pertanyíem a l'engranatge de l'escola; d'altra banda, durant les diferents visites que vam realitzar a les aules durant el procés de treball, érem considerades com a representants legítimes de la institució museística, les que els permetríem l'accés al museu i a la posterior pràctica expositiva. Des de la nostra posició com a educadores volíem trencar aquest esquema rígid dels dos posicionaments separats: el museu i l'escola. El nostre objectiu principal se centrà en la complicitat en tot moment amb les mestres i els alumnes, planificant les visites, assessorant i gestionant l'organització de l'exposició. Un dels aspectes que ens ajudà a entrar en una dinàmica de normalitat, entre les obres i els artistes del museu, ens la va proporcionar la participació i complicitat de l'artista Antonio Alcàsser, que va parlar en primera persona de la seva obra, la qual cosa afavorí el procés creatiu del nen.

Un dels punts més importants va ser el fet de considerar la llibertat en el procés creatiu dels alumnes: que ells poguessin desenvolupar la imaginació i els sentiments, representar -per mitjà d'una particular interpretació dels elements- línies, formes, colors, ritmes, masses, moviments, espais, coordinació, etc. Es va posar especial atenció a desenvolupar un ambient educatiu propici, adaptant cada espai per afavorir la descoberta del nen, creant noves situacions d'aprenentatge. No preteníem que els alumnes fessin una imitació de les obres, ni que es limitessin només a aplicar-ne els aspectes formals; es van donar les pautes per a l'experimentació i la manipulació dels materials per estimular la seva expressió i la pròpia inventiva sense la necessitat de voler controlar els resultats. Volíem transmetre la idea que les obres d'art tenen significats i valors, que van des de la mateixa producció intel-lectual i física de l'artista fins a arribar a la mirada de l'espectador, i que cadascuna d'aquestes mirades és única, vàlida i intransferible (BERGER, 2005). La particular producció dels nens i nenes és considerada com una forma d'aprenentatge (GARDNER, 1994), reinterpreta i crea nous significats a partir del seu coneixement i del seu bagatge cultural. El llenguatge artístic és un mitjà de coneixement que desenvolupa la capacitat creativa i conceptual. "Si els ulls d'altri mutilen l'obra de l'artista en la mesura que se l'apropien, també és cert que sense aquests altres ulls que la contemplen com a art, l'art no existiria" (LLENA, 1999).

A l'escola el treball es realitzà com una col-lectivitat. L'assessora de plàstica del centre s'implicà en el projecte, aconsellant i orientant sobre els diferents aspectes tècnics de la producció. També des del museu se'ls va acompanyar, aclarint en tot moment els seus dubtes. La institució estava a disposició del centre i es prenien seriosament el treball dels seus alumnes. Aquest fet, que per a molts pot semblar irrellevant, per als mestres i alumnes va ser molt important, ja que malauradament no estan habituats a aquest tracte: com que són petits, sembla que, com a tals, la societat en general no els acaba de prendre prou seriosament.

La llibertat d'actuació que se'ns donà per part de la direcció del museu, en l'elaboració del guió i dels contin- 


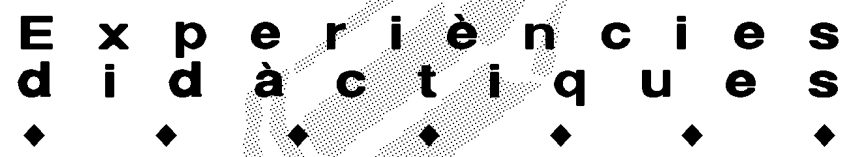

guts, facilità l'èxit del projecte. Era el moment d'entrar en joc per part de la resta de departaments i persones de la institució. Les educadores treballaren en tot moment, en col-laboració amb la resta de l'equip que muntava l'exposició, aportant noves idees i dissenyant materials educatius que possibilitaven un enfocament pedagògic del projecte. (JUANOLA i COLOMER, 2005).

La coordinació de l'exposició tingué cura de diversos aspectes:

- En primer lloc, la ubicació. Es pensà en un espai que tingués una bona accessibilitat per part de tot tipus de públic; els factors ergonòmics i la funcionalitat; si es tractava d'una exposició feta per nens i dirigida al públic escolar, la disposició dels treballs es faria en relació amb l'alçada dels seus ulls.

- Edició i tramesa de la invitació, un aspecte important: va ser el protagonisme dels nens i nenes que convidaven els familiars en la trobada al museu.
- Disseny i edició dels continguts de les banderoles temàtiques, on s'explica gràficament com es desenvolupen les activitats al museu.

- Elaboració dels cartells representants de cada aula, on constaven: el títol de l'activitat, el nivell del curs, el procés del treball individual i del treball col-lectiu, i els noms dels participants.

- Edició del fullet de mà. Les mestres van escriure un text explicatiu de com s'havia viscut aquesta experiència i què va significar aquest projecte per a l'escola.

- Disseny dels racons interactius, un espai concebut des de l'escola amb l'objectiu de fer participar tots el públics dels treballs dels nens i nenes. Una metodologia basada en l'observació i l'experimentació va portar els alumnes a la necessitat de crear aquests espais. Els nens miren, toquen, pregunten, experimenten... i així aprenen, així cons-

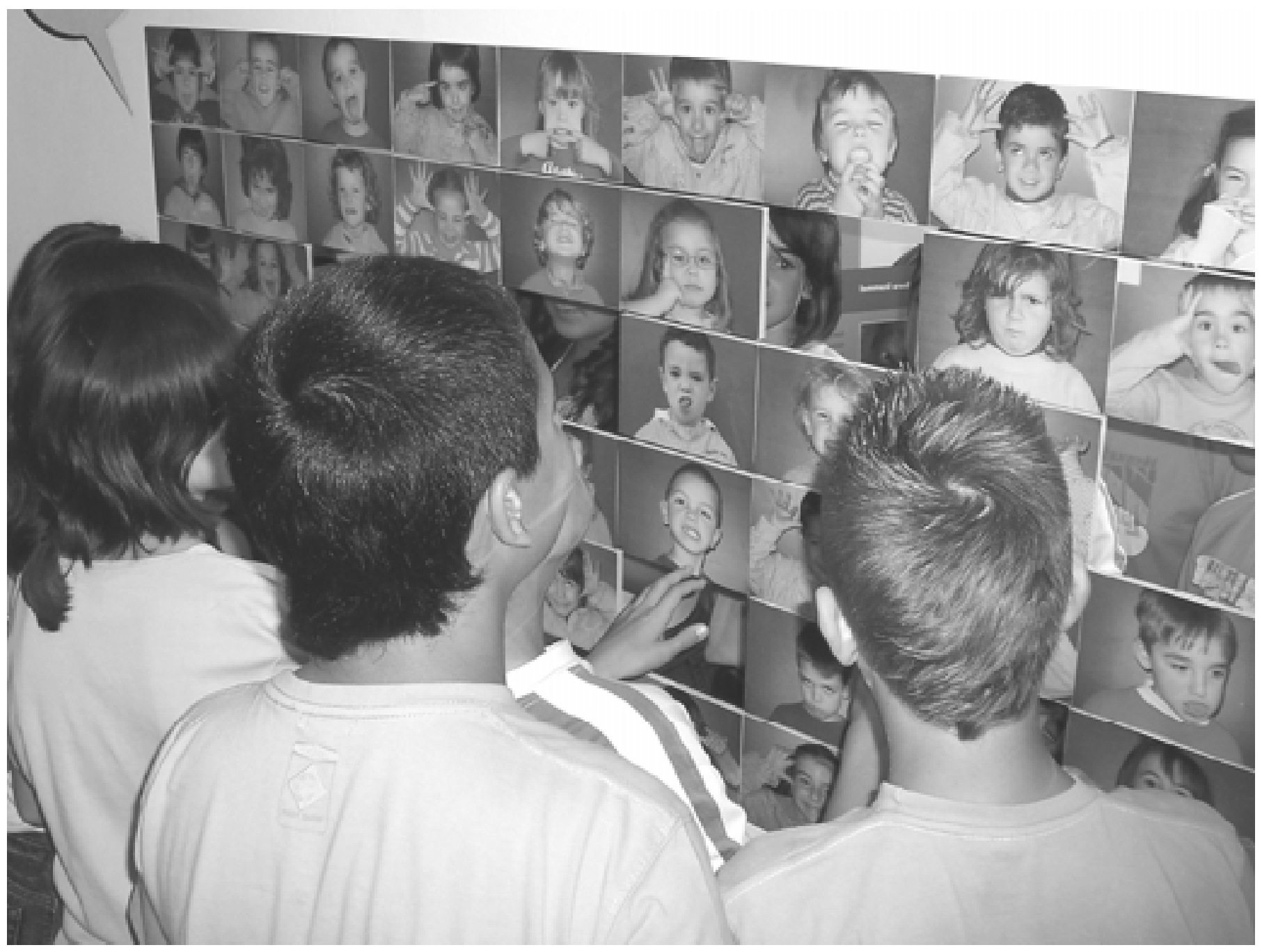




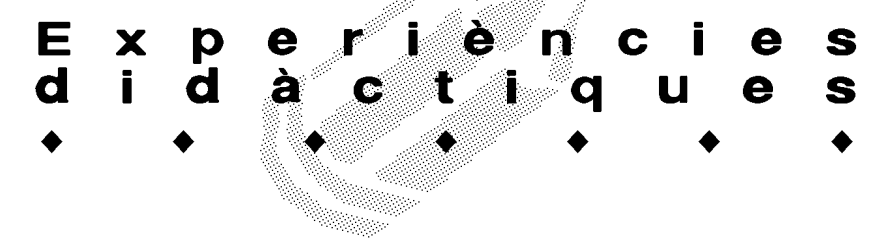

trueixen el seu propi món, així creixen com a persones. Per això, en aquesta exposició no hi podien faltar els racons interactius, pensats per als nens i nenes, i també per als adults, que potser de petits no van tenir l'oportunitat de visitar un museu que es pogués tocar.

- Elaboració de l'audiovisual: Imagina't que ets un artista... i que exposes al MAMT.

\section{Reflexions finals de l'escola i del museu}

Som conscients del benefici que ha reportat aquest projecte a la institució. Les visites dels familiars al museu i la bona acollida per part del públic han incrementat el seu prestigi i projecció social; la difusió en els diferents mitjans de comunicació ens va donar l'oportunitat d'explicar el projecte i parlar des dels dos posicionaments. Notàvem que alguna cosa s'havia mogut en la relació entre les mestres i les educadores del museu: treballar plegades ens ha permès copsar la realitat des dels nostres àmbits laborals, i ha estat un intercanvi profitós per a ambdues parts, que hem trobat en el museu un espai relacional i una eina necessària que pot superar les mancances en matèria d'educació artística que no es dóna des de l'educació formal. També ens ha permès traspassar les parets del museu i conèixer de més a prop la realitat de l'escola.

Aquest projecte ens ha donat la possibilitat de viure l'experiència de l'intercanvi intergeneracional; aquesta pràctica educativa ha portat les famílies a un mateix àmbit de participació i a una situació d'aprenentatge on els adults aprenen a través dels nens (HOOPERGREENHILL, 1998).

Hem copsat un canvi significatiu en la valoració de la pràctica de les educadores respecte als altres departaments del museu, interrelacionant diferents persones que han treballat conjuntament en el projecte: "Una visió objectiva del museu ens porta a integrar i valorar en un mateix pla d'igualtat totes les funcions, ja que el predomini d'unes sobre les altres ens dóna una visió esbiaixada de la institució... La col·laboració interdepartamental és imprescindible perquè el museu pugui complir els seus objectius i oferir un millor servei a la societat." (HERNÁNDEZ, 1994).

Des de la posició d'educadores aquesta experiència ens ha permès revisar la nostra pràctica, partint de la base que disposem d'un cert grau d'autonomia per emprendre les activitats educatives, la qual cosa ens permet assolir els objectius de la programació pedagògica. Però hem de destacar que en aquest projecte hem facilitat la utilització d'un espai per a la participació i l'entesa del grup, tractant cada individu d'igual a igual, possibilitant el diàleg a partir dels objectes del museu.
"[...] Entenem l'educador com un facilitador, un investigador, un intel-lectual crític la funció del qual és posar en pràctica un aprenentatge cooperatiu i estratègic." (KIVATINETZ i LÓPEZ, 2006).

L'associació entre l'escola i el museu, dues institucions amb especificitats i accions educatives diferents, ens ha permès presentar aquest projecte interdisciplinari a la comunitat educativa de la ciutat, fent realitat la seva continuïtat com a programació estable del museu i oferirlo a les escoles com una eina útil de treball per a una millor implementació de l'educació artística des de la pràctica. Que el museu sigui entès com una comunitat d'aprenentatge més que com una institució (PADRÓ, 2003). Hem de ser capaços d'unir esforços per treballar junts i negociar tant com calgui per incorporar els interessos recíprocs del museu (institució) i dels escolars (ciutadans).

\section{Referències bibliogràfiques}

BERGER, J. Modos de Ver. Edit. Gustavo Gili. Barcelona. 2005. DE CERTEAU, M. "De las prácticas cotidianas de oposición”. Dins BLANCO, B., CARRILLO, J., CLARAMONTE, J., EXPÓSITO, M. (2001) Modos de hacer. Salamanca: Universidad de Salamanca. Salamanca. 1990. Pàg. 391-425.

GARDNER, H. Educación artística y desarrollo humano. Edit. Paidós. Barcelona. 1994.

HERNÁNDEZ, F. Manual de Museología. Editorial Síntesis. Madrid. 1994. Pàg. 268-269.

HOOPER-GREENHILL, E. Los museos y sus visitantes. Ediciones Trea. Gijón. 1998. Pàg. 142.

JUANOLA, R. i COLOMER, A. "Museos y educadores perspectivas y retos de futuro". Dins HUERTA, R. i CALLE, R. (Eds.). La mirada inquieta, educación artística y museos. Universitat de València. València. 2005. Pàg.21-39.

KIVATINETZ, M. i LÓPEZ, E. Mirada crítica sobre la formación dels educadors de museus. [En línia]. «Zona Pública», Butlletí digital, 4 (2006) 13. [Data de consulta: 2012-07]. <http://www.museologia.org/docs/documents/zp/zp4/ Lopez_cat.pdf>.

LLENA, A. La gana de l'artista. Divagacions sobre art. Edicions 62. Barcelona. 1999. Pàg. 146-147.

MACAYA, A. i SUÁREZ, M. "Arte, museo y territorio". Dins CALAF, R., FONTAL, O. i VALLE, R. (Coords.) Museos de arte y educación: construir patrimonios desde la diversidad. Ediciones Trea. Gijón. 2007. Pàg. 205-217.

PADRÓ, C. "La museología crítica como una forma de reflexionar sobre los museos como zonas de conflicto en intercambio". Dins LORENTE, J. P. (Dir.). Museología crítica y arte contemporáneo. Edit. Prensas Universitarias de Zaragoza. Zaragoza. 2003. Pàg. 60.

PADRÓ, C. "Educación artística en museos y centros de arte". Dins HUERTA, R. i CALLE, R. (Eds). La mirada inquieta, educación artística y museos. Edit. Universitat de València. València. 2005. Pàg. 146-147.

PASTOR, I. Pedagogía museística: nuevas perspectivas y tendencias actuales. Edit. Ariel. Barcelona. 2004. Pàg. 56. 